Research Paper

\title{
Radiographic and Tomographic Analysis in Patients with Stickler Syndrome Type I
}

\author{
Ali Al Kaissi 1,2凶 , Farid Ben Chehida ${ }^{3}$, Rudolf Ganger 2, Vladimir Kenis ${ }^{4}$, Shahin Zandieh ${ }^{5}$, Jochen G \\ Hofstaetter 2, Klaus Klaushofer1, Franz Grill 2
}

1. Ludwig Boltzmann Institute of Osteology, at the Hanusch Hospital of WGKK and, AUVA Trauma Centre Meidling, First Medical Department, Hanusch Hospital, Vienna, Austria.

2. Orthopaedic Hospital of Speising, Paediatric Department, Vienna, Austria.

3. Institute of Radiology and Research -Ibn Zohr Centre of Radiology, Tunis, Tunisia.

4. Pediatric Orthopedic Institute n.a. H. Turner, Department of Foot and Ankle Surgery, Neuro-Orthopaedics and Systemic Disorders, Saint-Petersburg, Russia.

5. Department of Radiology-Hanusch Hospital; Vienna, Austria.

$\square$ Corresponding author: Dr Ali Al Kaissi, Ludwig-Boltzmann Institute of Osteology at the Hanusch Hospital of WGKK and AUVA Trauma Center Meidling, First Medical Department, Hanusch Hospital Vienna, Austria. Email: ali.alkaissi@osteologie.at; ali.alkaissi@oss.at.

() Ivyspring International Publisher. This is an open-access article distributed under the terms of the Creative Commons License (http://creativecommons.org/ licenses/by-nc-nd/3.0/). Reproduction is permitted for personal, noncommercial use, provided that the article is in whole, unmodified, and properly cited.

Received: 2012.08.07; Accepted: 2013.06.14; Published: 2013.08.03

\begin{abstract}
Objective: To further investigate the underlying pathology of axial and appendicular skeletal abnormalities such as painful spine stiffness, gait abnormalities, early onset osteoarthritis and patellar instability in patients with Stickler syndrome type I. Radiographic and tomographic analyses were organized.

Methods: From a series of Stickler syndrome patients followed from early life to late childhood. Ten patients ( 6 boys and four girls of different ethnic origins were consistent with the diagnosis of Stickler syndrome type I). Phenotypic characterization was the baseline tool applied for all patients and genotypic correlation was performed on four families

Results: A constellation of axial abnormalities namely; anterolateral ossification of the anterior longitudinal spinal ligament with subsequent fusion of two cervical vertebrae, early onset Forestier disease (progressive spinal hyperostosis with subsequent vertebral fusion on top of bridging osteophytes and "Bamboo-like spine" resembling ankylosing spondylitis) and severe premature spine degeneration were evident. Appendicular abnormalities in connection with generalized epiphyseal dysplasia were the underlying aetiology in patients with Intoeing gait and femoral anteversion, early onset severe osteoarthritis of the weight bearing joint. Remarkable trochleo-patellar dysplasia secondary to severe osteoarthritis causing effectively the development of patellar instability was additional pathology. Mutation of COL2AI has been confirmed as the causative gene for Stickler syndrome type I

Conclusion: We concluded that conventional radiographs and the molecular determination of a COL2AI in patients with (Stickler syndrome type I) are insufficient tools to explain the reasons behind the tremendous magnitude of axial and appendicular skeletal abnormalities. We were able to modify the criteria of the clinical phenotype as designated by Rose et al in accordance with the novel axial and appendicular criteria as emerged from within our current study.
\end{abstract}

Key words: Stickler syndrome type I; Mutation of COL2A1 gene; Premature spine degeneration; Forestier disease; Intoeing gait; Osteoarthritis; Patellar instability; CT scan.

\section{Introduction}

Stickler syndrome, designated hereditary progressive arthro-ophthalmopathy, is an autosomal

dominant connective tissue dysplasia characterized by flat midface, high myopia, retinal detachment, 
cataracts, hearing loss, arthropathy, and cleft palate (or bifid uvula) and musculoskeletal abnormalities $[1,2,3]$. Most patients are recognized in childhood if they present with cleft palate or severe ocular findings or have a positive family history. Approximately one fourth has an open cleft palate, and other patients have more subtle clefting (bifid ovula or submucus clefts) [4-6]. High myopia generally develops in early childhood and is associated with vitreous degeneration and a predisposition to retinal detachment and cataracts (excepting patients with type 2 or non-ocular Stickler syndrome). Stickler syndrome patients are usually tall and slender. The genetic defect in Stickler syndrome has highly variable phenotypic manifestations. There is a great diversity and severity of pathologic vitreous phenotype in association with Stickler syndrome [3,7]. Nearly all patients have evidence of mild spondyloepiphyseal dysplasia with frequent spinal abnormalities (scoliosis, Scheuremann-like kyphotic deformities, and spondylolisthesis) [8]. Premature osteoarthritis is common in Stickler syndrome, and there appears to be a predisposition to femoral head complications (Legg-Perthes like disease or slipped epiphysis), osteochondritis dissecans, Osgood Schlatter disease, protrusio acetabuli, slipped epiphyses, chondro-lysis, and osteopenia [9-12]. Forestier disease (diffuse skeletal hyperostosis) is a well-known radiographic diagnosis, usually seen in patients with abnormal metabolic parameters such as diabetes mellitus, hypercholesterolemia, hyperuricaimia and others $[13,14]$.

Intoeing is a frequent gait problem, usually encountered in children with cerebral palsy [15-18].

Patients with symptomatic patellar instability will have either objective patellar instability (true atraumatic dislocation with an anatomical abnormality) or potential patellar instability (pain, catching or locking of the patellofemoral joint and inability to rehabilitate quadriceps with an anatomical abnormality) [19]. In this paper we described the importance of comprehensive radiological and tomographic analysis of the various axial and appendicular abnormalities in patients with Stickler syndrome type I in order to further manage these patients properly.

\section{Materials and methods}

The study protocol was approved by the Medical University of Vienna (Ethics committee, EK Nr: $921 / 2009)$. Informed consents were obtained from the patients guardians. The original material comprised ten patients (six boys and four girls of different ethnic origins) evaluated between 2002 and 2011 at the Orthopaedic Hospital of Speising, department of "Bone Genetics", Vienna, Austria. The mean age was 8 years (range 1-19 years) and the mean age of first diagnosis was 4.7 years (range 1- 12 years). The diagnosis of Stickler syndrome type I was based on the details of the phenotype affecting the ocular, craniofacial, auditory, and musculoskeletal systems and highlighted by the intra-and inter-familial variability. Most patients are recognized in childhood if they present with cleft palate or severe ocular findings or have a positive family history. We modified the diagnostic criteria for type I Stickler syndrome as proposed by Rose et al [11] on the basis of our novel findings of the appendicular and axial skeletal systems.

Phenotypic characterization and conventional radiographs was the initial tool of assessment and diagnosis, followed by genotypic correlation in four families of our series (table 1). Computed tomography (CT scan) was the modality of choice. Patients were, thereafter, divided into three distinctive groups.

Group 1 included patients with early onset painful back stiffness. Some of the subjects in this group have been further investigated by means of reformatted CT scan to understand the etiology behind their early onset spine stiffness. Five children with the mean age of 7-19 have been identified because of generalized spine stiffness. Classically, the pathophysiology of the spinal abnormalities in Stickler syndrome has not been fully defined. Some researchers explained the spine pathology in patients with Stickler syndrome as it is because of the fibrillar collagen mutations associated with the syndrome (COL2A1, COL11A1, and COL11A2). Their beliefs were based on that the malformation is due to weakening of the intervertebral disks and the vertebral end plates $[8,9]$.

Group 2 included patients with abnormal gait (Intoeing gait and femoral anteversion). Several reports in the literature have attributed the internal rotation and the intoeing gait as a common feature in patients with cerebral palsy because of spastic medial hamstrings and the adductors and to spastic gluteus medius and minimus muscles [15-18].

Two male patients of 13 and 19 years respectively presented with gait abnormalities (intoeing gait and femoral anteversion) were further investigated via CT scanning.

Group 3 included patients presented with early onset severe osteoarthritis (We considered a patient to have osteoarthritis on radiograph of the hip or knee, if the score was 2 or higher in accordance with Kellgren-Lawrence scoring system (seven patients were included in this group). Radiographs in this respect were able to directly visualized osseous features of osteoarthritis, including marginal osteophytes and subchondral sclerosis. Joint space assessment on radiographs and sky-line images was found to be reliable for evaluating the anatomic severity of osteoar- 
thritis. Patients in this group manifested pain along the weight bearing joints which get relatively less by taking non-steroidal anti-inflammatory medications. Measurements of the Kellgren and Lawrence score to quantify osteoarthritis of the hip and knee have been applied [20]. Also patients with patella-trochlear dysplasia secondary to severe osteoarthritis instability were included (patellar stability is defined as it relies on the limb alignment, the osseous architecture of the patella and the trochlea, the integrity of the soft tissue constraints, and the interplay of the surrounding muscles) [21]. This subgroup of patients was assessed by conventional radiographs and by $\mathrm{CT}$ scanning.

Table I. summarizes the phenotypic characterization of Stickler syndrome type I in our patients as designated by Rose et al [II] and modified by Al Kaissi et al.

\begin{tabular}{|c|c|c|c|c|c|c|c|c|c|c|c|}
\hline $\begin{array}{l}\text { Pa- } \\
\text { tients }\end{array}$ & $\begin{array}{l}\text { age } \\
\text { year }\end{array}$ & $\begin{array}{l}\text { Phenotyp- } \\
\text { ic-Genotypic } \\
\text { correlation }\end{array}$ & $\begin{array}{l}\text { Cleft pal- } \\
\text { ate/Bifid } \\
\text { ovula }\end{array}$ & $\begin{array}{l}\text { Ocular } \\
\text { abnormali- } \\
\text { ties }\end{array}$ & $\begin{array}{l}\text { Auditory } \\
\text { abnormalities }\end{array}$ & Spine & $\begin{array}{l}\text { Scolio- } \\
\text { sis/Kyphos } \\
\text { is }\end{array}$ & $\begin{array}{l}\text { Scheuer- } \\
\text { mann-like } \\
\text { deformities }\end{array}$ & $\begin{array}{l}\text { Early } \\
\text { onset } \\
\text { oteoar- } \\
\text { thritis }\end{array}$ & $\begin{array}{l}\text { Gait abnor- } \\
\text { malities }\end{array}$ & $\begin{array}{l}\text { Patellar } \\
\text { instability }\end{array}$ \\
\hline $\begin{array}{l}\text { Pateint } \\
\text { I }\end{array}$ & 1 & $\begin{array}{l}\text { Phenotypic } \\
\text { and mutation } \\
\text { of COL } 2 A 1\end{array}$ & $\begin{array}{l}\text { Pierre-Rob } \\
\text { in se- } \\
\text { qunece }\end{array}$ & $\begin{array}{l}\text { Congenital } \\
\text { glaucoma }\end{array}$ & $\begin{array}{l}\text { Hypermobile } \\
\text { tympanic } \\
\text { membrane }\end{array}$ & $\begin{array}{l}\text { Platyspon- } \\
\text { dyly }\end{array}$ & $\begin{array}{l}\text { Thoracic } \\
\text { kyphosis }\end{array}$ & +++ & - & - & - \\
\hline $\begin{array}{l}\text { Pateint } \\
\text { II }\end{array}$ & 5 & $\begin{array}{l}\text { Phenotypic } \\
\text { characteriza- } \\
\text { tion }\end{array}$ & $\begin{array}{l}\text { Cleft pal- } \\
\text { ate }\end{array}$ & $\begin{array}{l}\text { Myopia \& } \\
\text { astigma- } \\
\text { tism }\end{array}$ & $\begin{array}{l}\text { Hypermobile } \\
\text { tympanic } \\
\text { membrane }\end{array}$ & $\begin{array}{l}\text { Platyspon- } \\
\text { dyly }\end{array}$ & $\begin{array}{l}\text { Thoracic } \\
\text { kyphosis }\end{array}$ & +++ & - & Waddling & - \\
\hline $\begin{array}{l}\text { Patient } \\
\text { III }\end{array}$ & 5 & $\begin{array}{l}\text { Phenotypic } \\
\text { characteriza- } \\
\text { tion }\end{array}$ & $\begin{array}{l}\text { Cleft pal- } \\
\text { ate }\end{array}$ & Myopia & $\begin{array}{l}\text { Conductive } \\
\text { hearling loss }\end{array}$ & $\begin{array}{l}\text { Platyspon- } \\
\text { dyly }\end{array}$ & Scoliosis & + & - & - & - \\
\hline $\begin{array}{l}\text { Patient } \\
\text { IV }\end{array}$ & 7 & $\begin{array}{l}\text { Phenotypic } \\
\text { characteriza- } \\
\text { tion }\end{array}$ & $\begin{array}{l}\text { Cleft pal- } \\
\text { ate }\end{array}$ & Myopia & $\begin{array}{l}\text { Conductive } \\
\text { hearling loss }\end{array}$ & $\begin{array}{l}\text { Platyspon- } \\
\text { dyly }\end{array}$ & Scoliosis & + & ++ & Waddling & + \\
\hline $\begin{array}{l}\text { Patient } \\
\mathrm{V}\end{array}$ & 9 & $\begin{array}{l}\text { Phenotypic } \\
\text { and mutation } \\
\text { of } C O L 2 A 1\end{array}$ & $\begin{array}{l}\text { Cleft pal- } \\
\text { ate }\end{array}$ & Myopia & $\begin{array}{l}\text { Hypermobile } \\
\text { tympanic } \\
\text { membrane }\end{array}$ & $\begin{array}{l}\text { Platyspon- } \\
\text { dyly-Giant } \\
\text { bridging } \\
\text { osteophytes }\end{array}$ & Kyphosis & +++ & +++ & $\begin{array}{l}\text { Stooped posi- } \\
\text { tion and cal- } \\
\text { caneovalgus } \\
\text { deformity of } \\
\text { the ankles and } \\
\text { marked oste- } \\
\text { oporosis }\end{array}$ & $\begin{array}{l}\text { Patel- } \\
\text { lo-trochle } \\
\text { ar dyspla- } \\
\text { sia }\end{array}$ \\
\hline $\begin{array}{l}\text { Patient } \\
\text { VI }\end{array}$ & 13 & $\begin{array}{l}\text { Phenotypic } \\
\text { characteriza- } \\
\text { tion }\end{array}$ & $\begin{array}{l}\text { Bifid ovu- } \\
\text { la }\end{array}$ & $\begin{array}{l}\text { Myopia \& } \\
\text { astigma- } \\
\text { tism }\end{array}$ & $\begin{array}{l}\text { Conductive } \\
\text { hearling loss }\end{array}$ & $\begin{array}{l}\text { Platyspon- } \\
\text { dyly }\end{array}$ & - & - & +++ & Intoeing gait & $\begin{array}{l}\text { Patel- } \\
\text { lo-trochle } \\
\text { ar dyspla- } \\
\text { sia }\end{array}$ \\
\hline $\begin{array}{l}\text { Patient } \\
\text { VII }\end{array}$ & 13 & $\begin{array}{l}\text { Phenotypic } \\
\text { characteriza- } \\
\text { tion }\end{array}$ & $\begin{array}{l}\text { Cleft pal- } \\
\text { ate }\end{array}$ & Myopia & - & $\begin{array}{l}\text { onset senile } \\
\text { hyperostosis } \\
\text { (Forsteir } \\
\text { disease) }\end{array}$ & Kyphosis & +++ & +++ & Intoing gait & +++ \\
\hline $\begin{array}{l}\text { Patient } \\
\text { VIII }\end{array}$ & 15 & $\begin{array}{l}\text { Phenotypic } \\
\text { and mutation } \\
\text { of COL } 2 A 1\end{array}$ & $\begin{array}{l}\text { Cleft pal- } \\
\text { ate }\end{array}$ & $\begin{array}{l}\text { Myopia and } \\
\text { family } \\
\text { history of } \\
\text { retinal } \\
\text { detachment }\end{array}$ & $\begin{array}{l}\text { Conductive } \\
\text { hearling loss }\end{array}$ & $\begin{array}{l}\text { Bamboo-like } \\
\text { spine }\end{array}$ & Scoliosis & - & +++ & $\begin{array}{l}\text { Stooped posi- } \\
\text { tion }\end{array}$ & +++ \\
\hline $\begin{array}{l}\text { Patient } \\
\text { IX }\end{array}$ & 17 & Phenotypic & $\begin{array}{l}\text { Bifid ovu- } \\
\text { la }\end{array}$ & $\begin{array}{l}\text { Myopia and } \\
\text { family } \\
\text { history of } \\
\text { retinal } \\
\text { detachment }\end{array}$ & Hearing loss & $\begin{array}{l}\text { Giant bridg- } \\
\text { ing osteophyt }\end{array}$ & Scoliosis & - & +++ & Waddling gait & +++ \\
\hline $\begin{array}{l}\text { Patient } \\
X\end{array}$ & 19 & $\begin{array}{l}\text { Phenotypic } \\
\text { and mutation } \\
\text { of } C O L 2 A 1\end{array}$ & $\begin{array}{l}\text { Cleft pal- } \\
\text { ate }\end{array}$ & $\begin{array}{l}\text { Myopia -15 } \\
\text { diopters }\end{array}$ & $\begin{array}{l}\text { Conductive } \\
\text { hearling loss }\end{array}$ & $\begin{array}{l}\text { Platyspon- } \\
\text { dyly and } \\
\text { early onset } \\
\text { senile hyper- } \\
\text { ostosis } \\
\text { (Forsteir } \\
\text { disease) }\end{array}$ & Scoliosis & - & +++ & $\begin{array}{l}\text { Stooped posi- } \\
\text { tion }\end{array}$ & +++ \\
\hline
\end{tabular}




\section{Results}

Group 1: Progressive spinal hyperostosis (Forestier disease) secondary to ossification of the anterior longitudinal spinal ligament associated with bridging osteophytosis were the main pathological processes behind the development of stiff and painful back bone in these patients. Forestier disease (diffuse skeletal hyperostosis) is a well-known radiographic diagnosis, usually seen in patients with abnormal metabolic parameters such as diabetes mellitus, hypercholesterolemia, hyperuricaimia and others. The condition is a systemic, non-inflammatory disorder. Ossification starts and extends from the insertions of skeletal muscles, ligaments, and joint capsules $[13,14]$.

Reformatted CT scan of the cervical spine in a 13-year-old girl showed anterolateral ossification of the anterior longitudinal spinal ligament (Forestier -like disease) with subsequent development of fusion-like abnormality (fig 1).

Sagittal reformatted spinal CT scan in a 9-year old boy showed, platyspondyly, extensive endplate sclerosis and anterior spurring and severe irregularities/fragmentations of the anterior and the posterior end-plates respectively associated with giant (bridging) osteophytes formation and Schmorl's nodes overwhelmed by severe premature degeneration associated with narrowing of the intervertebral disc spaces. Note vertebral scalloping of the posterior vertebral wall along the lower lumbar vertebrae (arrows) (fig 2).

3D reformatted coronal CT scanning in a 15-year-old girl showed extensive hyperostosis of the anterior longitudinal spinal ligaments, resulting in the characteristic radiographic finding of a Bamboo-like spine resembling ankylosing spondylitis, the overall spine pathology is compatible with severe premature spine degeneration overwhelmed by diffuse hyperostosis (fig 3).

These children showed negative rheumatologic parameters and their HLA-B27 was negative as well. It was important to us, to differentiate vertebral fusion in connection with early onset spinal hyperostosis from the congenital form of block vertebrae as seen in Klippel-Feil syndrome.

Group 2: Patients showed excessive femoral anteversion of the hips secondary to significant acetabulo-femoral dysplasia (IR-internal rotation: 90 degrees, ER-external rotation: 30 degrees). We measured the torsion of the femur by means of CT scan. There was femoral anteversion of right hip of $38^{\circ}$ and of the left hip of $45^{\circ}$ respectively in a 13-year-old-boy (fig 4 ). CT scan to measure the rotation of the knees showed internal rotation $7^{\circ}$ of the right knee and $20^{\circ}$ rotation of the left knee in connection with trochlear dysplasia (fig 5).

Group 3: To further delineate the joint pathology; Anteroposterior pelvis radiograph showed significant epiphyseal dysplasia associated with extensive fragmentation in a 19-year-old girl. This patient showed severe osteoarthritis (defined as the presence of hip pain and radiographic features of marked degenerative changes using Kellgren-Lawrence scoring system). The grade of osteoarthritis in these children was compatible with grade 3 of Kellgren-Lawrence score. Large osteophytes associated with marked narrowing of the joint spaces, sclerosis and subsequent deformity of the bony contour, coxa valga and osteopenia were present (fig 6).

Patellar instability has been referred to patello-trochlear dysplasia (anterior knee pain associated with patellar instability) in connection with joint hypermobility and epiphyseal dysplasia has been encountered in all patients. Lateral knee radiograph showed trochlear dysplasia, including the crossing sign, supratrochlear spur, and double contour (a hypoplastic medial facet) associated with patellar dysplasia and patellar maltracking in a 9-year-old patient (fig 7). The skyline view in female patient aged 17-years-old showed mal- tracking of the patella with trochlear dysplasia associated with severe hyperpression of the patello- femoral joint, with subchondral degenerative changes (this is a common feature in patients with patellar instability in connection with patello-trochlear dysplasia associated with profound femoral notching), also, this is compatible with osteoarthritis of the patella-femoral joint (fig 8).

Sky line-view in a male patient aged 19- years showed bilateral and symmetrical trochlear hypoplasia (flattened trochlea) with subsequent development of patellar instability (fig 9). Sky-line view in a-7-year-old boy showed severe trochlear dysplasia with subsequent patellar mal-tacking associated with significant osteoporosis (fig 10).

A-9-year-old boy with Stickler syndrome type I manifested premature osteoarthritis matching grade II of Kellgren-Lawrence grading scale with marked narrowing of the joint spaces associated with osteoporosis and coxa valga. Note the flattening of the capital femoral epiphysis, valgus deformity of the tibia, severe valgus of the ankle joint and calcaneovalgus deformity of both feet. Gradual deformity correction by temporary hemiepiphysiodeses of the proximal and distal medial epiphyses using 8 plates was performed to realign the lower limbs and to enable the child to walk and to lessen pain (fig 11)

Laboratory investigations: All our patients underwent a series of biochemical parameter assessments. Serum and urinary oligosaccharides, mucopolysaccharides, serum lactate, pyruvate, creatine 
phosphokinase, alkaline phosphatase, calcium, phosphorus, and vitamin D metabolism and chromosomal studies, all were within the normal range. Hormonal investigations included thyroid hormones; adrenocorticotropic hormone and growth hormone were negative as well. Erythrocyte sedimentation rate (ESR) was unremarkable and ranged between 10-15 $\mathrm{mm} / 1^{\text {st }}$ hour. Antinuclear antibody (ANA) and rheumatoid factors (FR) were negative. Genetic tests showed mutation of COL2A1 (this form of mutation is usually the result of premature termination codons and nonsense mediated decay resulting in haploinsufficiency of type II collagen), four families underwent genetic tests.

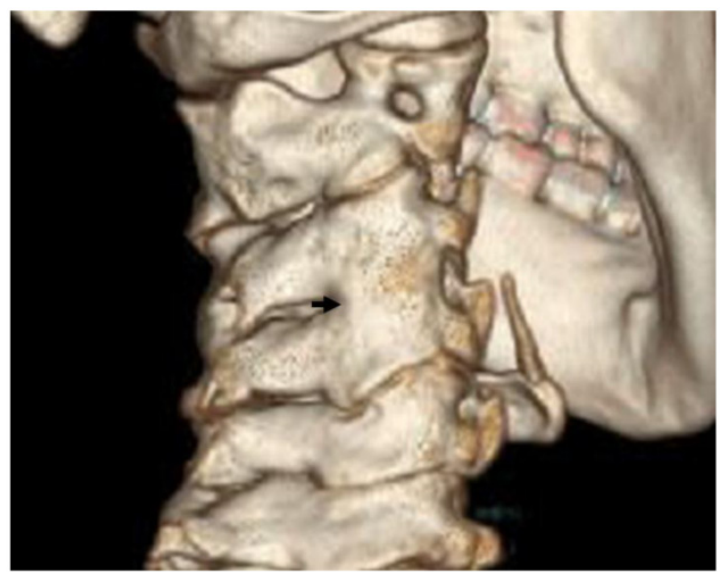

Fig I. Reformatted CT scan of the cervical spine in a 13-year-old girl showed anterolateral ossification of the anterior longitudinal spinal (Forestier disease) (arrow).

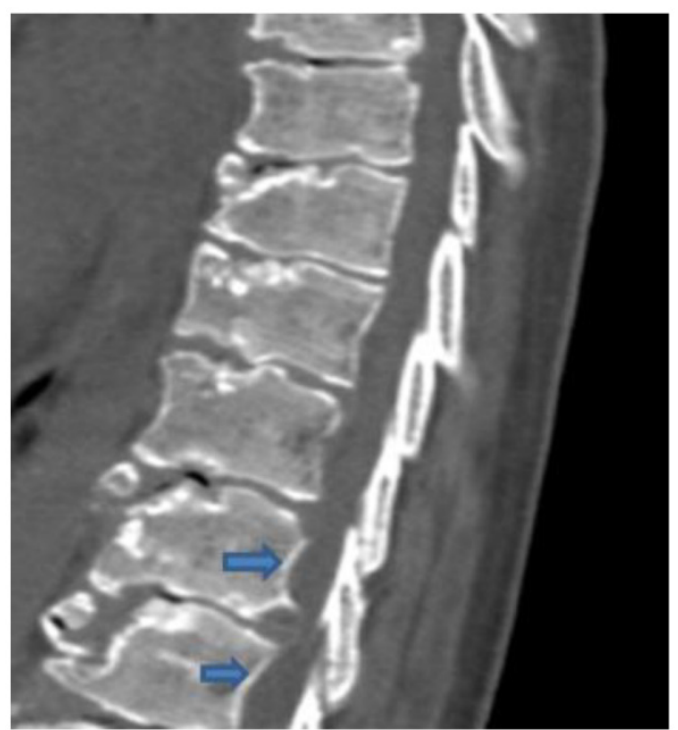

Fig 2. Sagittal reformatted spinal CT scan in a 9-year old boy showed, platyspondyly, extensive endplate sclerosis and anterior spurring associated with giant osteophytes formation, and Schmorl's nodes associated with narrowing of the intervertebral disc spaces. Note the development of vertebral scalloping along the lower lumbar vertebrae (arrows).

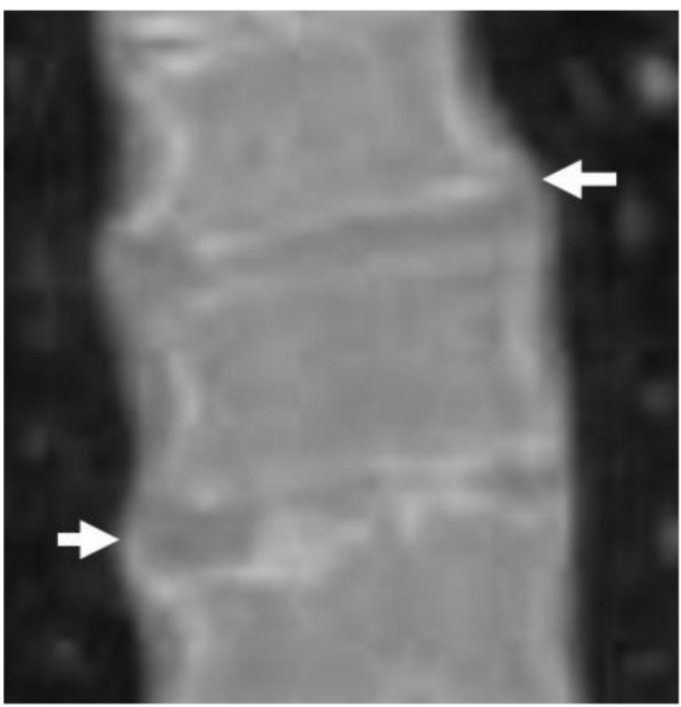

Fig 3. 3D reformatted coronal CT scanning in a 15 -year-old girl showed extensive hyperostosis of the anterior longitudinal spinal ligaments, resulting in the characteristic radiographic finding of a Bamboo-like spine resembling ankylosing spondylitis, the overall spine pathology is compatible with severe premature spine degeneration overwhelmed by diffuse hyperostosis (arrows).

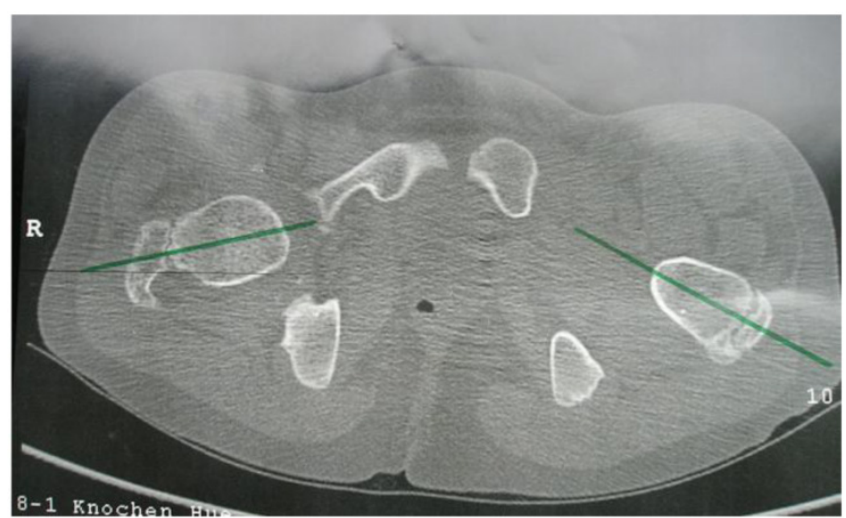

Fig 4. Axial hip CT scan showed femoral anteversion of the hips secondary to significant acetabulo-femoral dysplasia (IR-internal rotation: 90 degrees, ER-external rotation: 30 degrees). We measured the torsion of the femur by means of $C T$ scan. There was femoral anteversion of right hip of $38^{\circ}$ and of the left hip of $45^{\circ}$ respectively in a 13-year-old-boy.

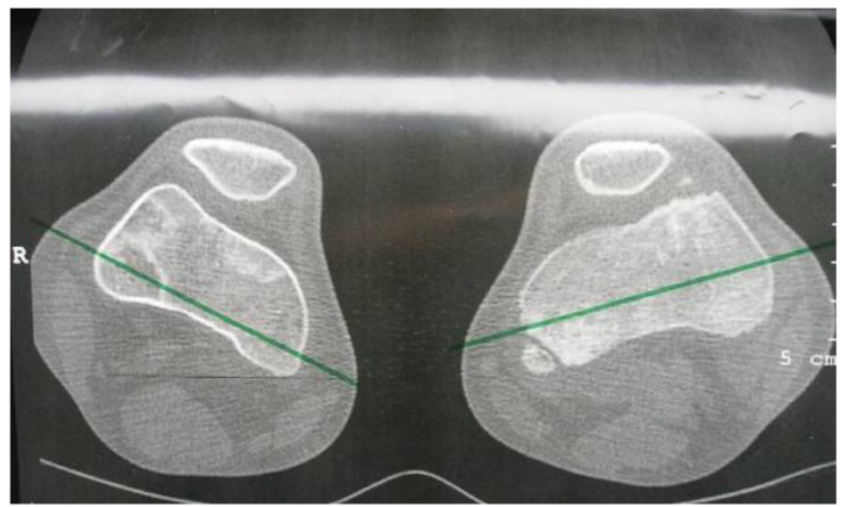

Fig 5. Axial CT scan of the knees showed internal rotation $7^{\circ}$ of the right knee and $20^{\circ}$ rotation of the left knee, note the epiphyseal fragmentations associated with trochlear dysplasia. 


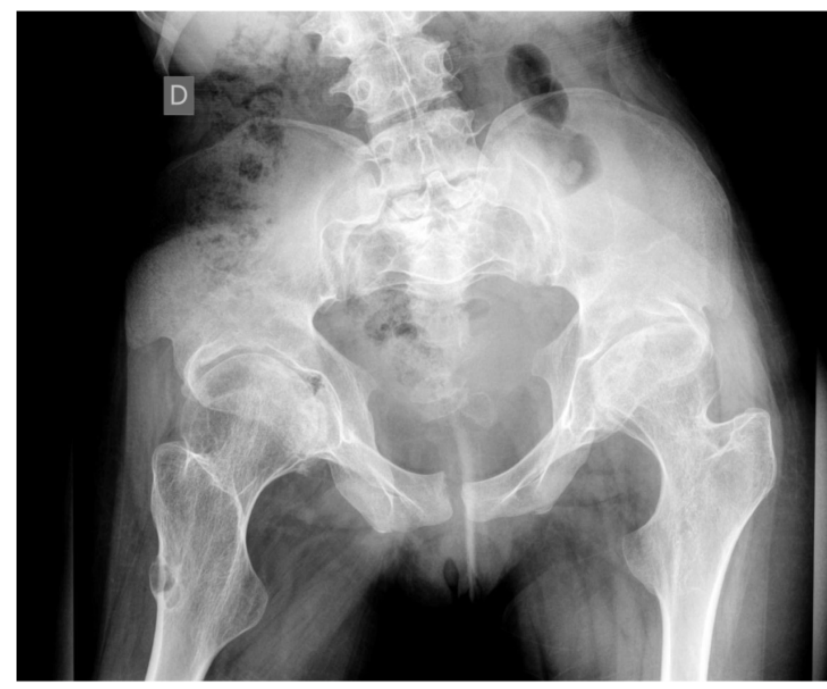

Fig 6. Anteroposterior hip radiograph in a 19-year-old girl showed severe osteoarthritis matching the grade III of Kellgren-Lawrence grading scale. Note the flattened and dysplastic epiphyses associated with large osteophytes with marked narrowing of the joint spaces, sclerosis and subsequent deformity of the bony contour, coxa valga and osteopenia.

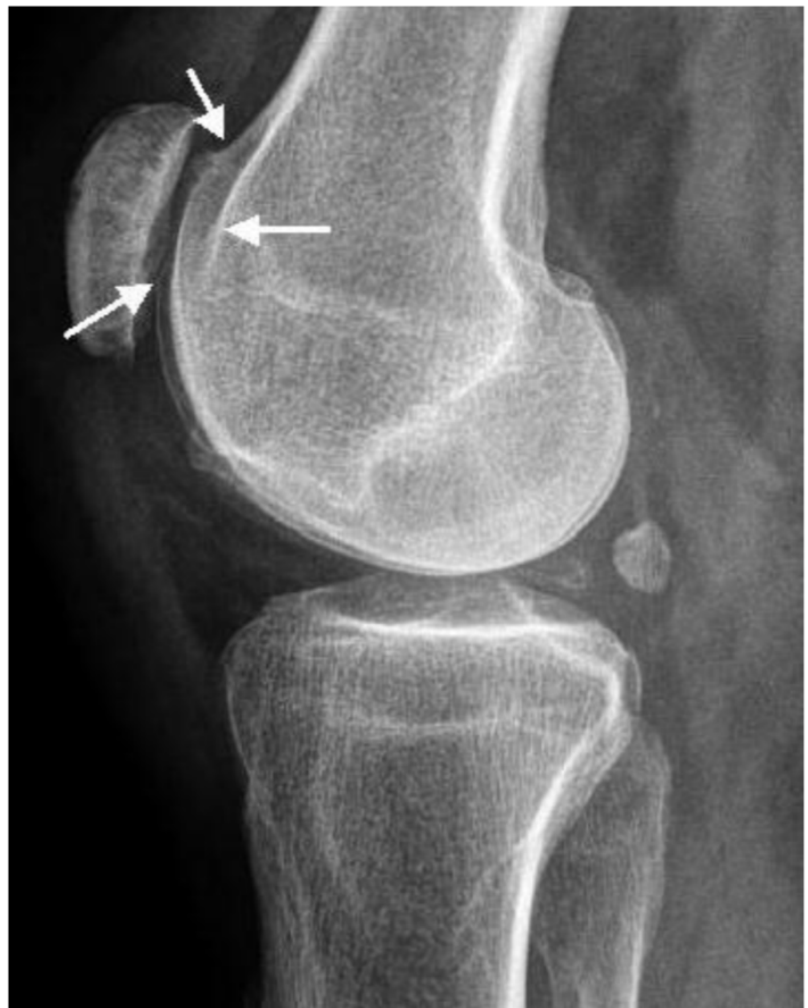

Fig 7. Lateral knee radiograph showed trochlear dysplasia, including the crossing sign, supratrochlear spur, and double contour (a hypoplastic medial facet) associated with patellar dysplasia and patellar maltracking in a 9-year-old-patient.

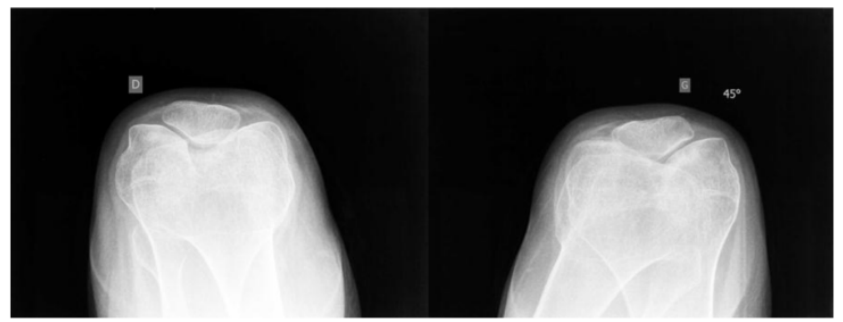

Fig 8. Skyline view showed mal- tracking of the patella with trochlear dysplasia and hyperpression of the patello- femoral joint, with subchondral degenerative changes (this is a common feature in patients with patellar instability in connection with patello-trochlear dysplasia). Also, this compatible with osteoarthritis of the patello- femoral joint in a 15 -year-old patient.

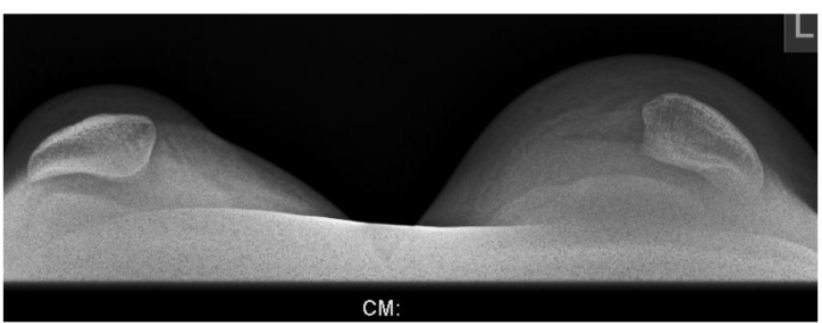

Fig 9. Sky line-view in patient showed bilateral and symmetrical trochlear hypoplasia (flattened trochlea) with subsequent development of patellar instability in a 19-year-old patient.

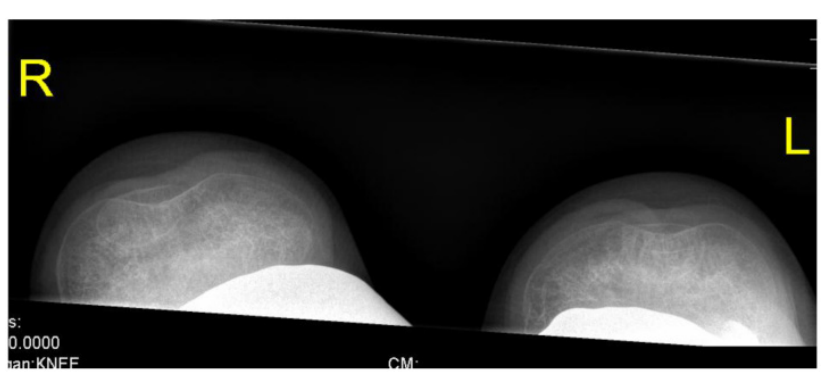

Fig 10. Sky-line view in a-7-year-old boy showed severe patellar- trochlear dysplasia with subsequent patellar mal-tacking associated with significant osteoporosis.

Fig I I. A-9-year-old boy with Stickler syndrome type I manifested premature osteoarthritis matching grade II of Kellgren-Lawrence grading scale with marked narrowing of the joint spaces associated with marked osteoporosis and coxa valga. Note the flattening of the capital femoral epiphysis, valgus deformity of the tibia, severe valgus of the ankle joint and calcaneovalgus deformity of both feet. Gradual deformity correction by temporary hemiepiphysiodeses of the proximal and distal medial epiphyses using 8 plates was performed to realign the lower limbs and to enable the child to walk and to lessen pain.

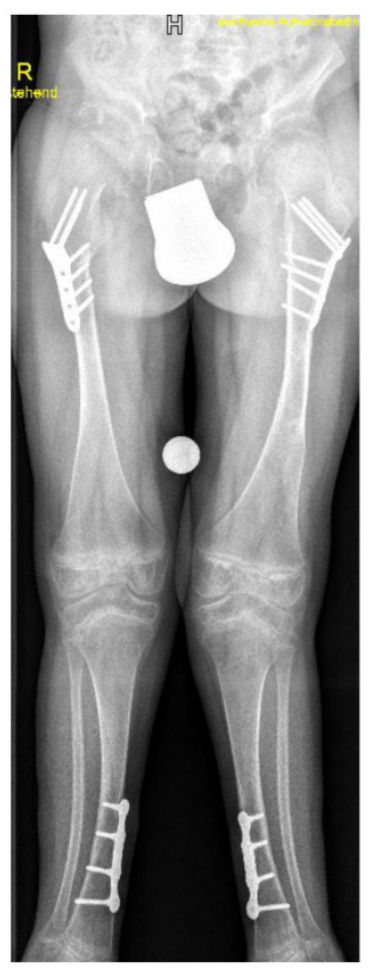




\section{Discussion}

Stickler et al reported wide phenotypic variability, which often resulted in delayed or missed diagnosis in many cases. Certain clinical findings, however, are consistent: 95\% ocular problems (retinal detachment in $60 \%$, myopia in $90 \%$, and blindness in $4 \%$ ); $84 \%$ facial abnormalities (flat nose, small mandible, or cleft palate); $70 \%$ hearing loss; $90 \%$ degenerative joint disease and pain. Stickler syndrome is an autosomal dominant disease characterized by midfacial flattening and variable disorders of vision, hearing and articulation. There is great diversity and severity of pathologic articular conditions in patients with Stickler syndrome. Most patients are recognized in childhood if they present with cleft palate or severe ocular findings or have a positive family history. Approximately one fourth has an open cleft palate, and other patients have more subtle clefting (bifid ovula or submucus clefts) [1,2].

The pathophysiology of the spinal abnormalities in Stickler syndrome has not been fully defined. Fibrillar collagen mutations associated with the syndrome (COL2A1, COL11A1, and COL11A2) presumably lead to malformation and weakening of intervertebral disks and vertebral end plates. Rose et al assumed that the vertebral abnormality is probably a result of abnormal vertebral growth with exacerbation by premature degenerative changes in adulthood [8].

Rose et al [8] evaluated the thoracolumbar spinal abnormalities in 53 patients from 24 families with Stickler syndrome (age range, 1-70 years). They found that $34 \%$ of patients had scoliosis, $74 \%$ endplate abnormalities, $64 \%$ Schmorl's nodes, 43\% platyspondylia, and $43 \%$ Scheuremann-like kyphosis. Sixty seven percent of patients and $85 \%$ of adults reported chronic back pain. Endplate abnormalities and Schmorl's nodes, have been described in old-age group of patients via conventional radiographs. In our patients early onset spine stiffness and the profound vertebral anatomical abnormalities were in connection with Forestier disease giant osteophytes formation, extensive end-plate abnormalities and the early development of Forestier disease.

Progressive spinal hyperostosis secondary to ossification of the anterior longitudinal spinal ligament is a well-known radiographic diagnosis encountered in older patients. The condition is a systemic, non-inflammatory disorder. Ossification starts and extends from the insertions of skeletal muscles, ligaments, and joint capsules. The most prominent features of the disease appear on the spine as contiguous formation of newly formed ectopic bone, along the anterolateral aspect of the spine. The cause and pathogenesis of this disease are still unknown $[13,14]$.
Our patients manifested radiographic features compatible with an unusually early onset hyperostosis resembling Forestier disease [13] in that there was ossification along the anterolateral aspects of the cervical and the thoraco-lumbar spine. Interestingly, we observed significant hyperostosis along the thoracic spine mimicking a "Bamboo spine" seen in patients with ankylosing spondylitis, however, our patients showed negative rheumatologic results and normal metabolic parameters. Moreover, they manifested abnormal vertebral growth and the severe premature degeneration was accompanied by severe erosions and irregularities of the anterior end-plates associated with eventual disc-space obliteration and fusions overwhelmed by significant hyperostosis at different spine levels.

Rose et al [9] reviewed the hip abnormalities on 59 patients from 25 families with Stickler syndrome. Ten percent had protrusio acetabuli, $21 \%$ coxa valga, and $34 \%$ of adults had hip osteoarthritis. Sixty-three percent of all patients and $79 \%$ of adults had chronic hip pain. Arthritic changes and adult age were associated with hip pain in adult patients with all types of Stickler syndrome. Our patients were selected among the Pediatric group of Stickler syndrome type I only, moreover adults have been excluded. Premature degenerative changes have been adequately demonstrated in our patients via conventional radiographs and CT scanning. Al Kaissi et al [12] described the correlation of severe undermineralization of the bone matrix and the compromised mechanical competence in a patient with Stickler syndrome type I. They, concluded that the development of appendicular skeletal abnormalities in Stickler syndrome (type I) were sequelae of poor anatomical arrangements at the epimetaphyseal junction. These results are consistent with a state of organic bone matrix deficits. The diminished mineral deposition may be attributable to a fundamental defect in bone development and mineralization that is related to the connective tissue disorder, which is a direct consequence of the presumed genetic mutation in COL2A1 [12]. These conclusions were found to be compatible with the genetic mutations of COL2A1 in our patients.

Intoeing is one of the most common conditions encountered in paediatric orthopaedic practice. It is important to make a definite diagnosis to elicit the underlying pathological process. In infants; the most common cause is metatarsus adductus. When present in the second year of life, intoeing is commonly due to internal tibial torsion. After 3 years of age, this problem is usually due excessive femoral anteversion. Intoeing is a frequent gait problem in children with cerebral palsy. Management is based on the understanding the causes and the natural course of the 
condition and the effectiveness of various treatment modalities [15-18]. Tonnis and Heinecke have shown that an increased or decreased femoral anteversion is associated with degenerative hip joint disease without giving further aetiological explanation [15].

In our patients femoral anteversion was correlated with generalized epiphyseal dysplasia and fragmentations along the capital femoral epiphyses, the acetabulae and the inferior femoral/tibial epiphyseal dysplasias were manifestations of Stickler syndrome type I. Clear differentiation of skeletal dysplasias from femoral anteversion and or other hip/knee deformities requires careful phenotypic interpretation and characterization. Therefore, it is empirical to delineate the underlying pathology because the prognosis of skeletal dysplasias compared with the several causations of hip deformities requires prompt indication for a precise therapeutic intervention is more guarded [18].

Patellar stability relies on the limb alignment, the osseous architecture of the patella and the trochlea, the integrity of the soft tissue constraints, and the interplay of the surrounding muscles. Patellofemoral dysplasia refers to a spectrum of anatomic abnormalities leading to anterior knee pain frequently associated with varying degrees of patellar instability. Disorders such as patellofemoral dysplasia, osteochondritis dessicans, chondromalacia patella, osteoarthritis, subluxation of the patella and dislocation of the patella are usually causing cartilage damage [19]. Patellofemoral osteoarthritis is a frequent clinical diagnosis associated with disability and often independent of tibiofemoral disease. The manifestation of patellofemoral osteoarthritis across the articulating surfaces of the joint is disparate, the patella demonstrating more severe signs of degeneration at a younger age or shorter time after injury compared with the juxtaposed femoral groove. Investigation into this disparity may hold crucial insights into the aetiology of osteoarthritis [20].

Patello-trochlear dysplasia with subsequent patellar maltracking and instability was identified in three patients. Previous reports described trochlear dysplasia as an abnormality of the shape and depth of the trochlear groove mainly in its proximal extent in non-syndromic patients (this was defined radiolgically by Dejour et al on the basis of the crossing sign "croisement" [21].

Our patients demonstrated the combination of patellar instability, maltracking and severe early onset osteoarthritis in correlation with severe trochlear dysplasia. We believe that patellofemoral dysplasia and patellofemoral osteoarthritis are typical manifestations in association with dysplastic trochlea in patients with Stickler syndrome. The anlage of the pa- tella starts to form as early as the sixth week of fetal life by detachment from the anlage of the lower part of the femur, which takes place proximal to the region of the future joint and then descends by the third month of fetal life and lies in the depression between the future femoral condyles. The patellar instability in our patients emerged in connection with severe trochlear dysplasia. The latter should be differentiated from the more common and better known nail patella syndrome, ischio-pubic-patellar syndrome, Meier-Gorlin syndrome, Genito-patellar syndrome, and Coffin-Siris syndrome [22,23,24].

\section{In summary}

We emphasize the importance of proper phenotypic characterization of children who are considered as chronic clients at the departments of ophthalmology, rheumatology and or orthopedics. In addition, the role of $\mathrm{CT}$ scanning in the investigation of patients with skeletal dysplasias is fundamental to improve our understanding of the underlying pathology, and to comprehend the various stages of the bone pathophysiology. We wish to stress, that bone is a dynamic tissue, which throughout life, bone tissue is continually being formed and resorbed. This remodeling and reorganization is notoriously unpredictable mechanism, particularly in patients with connective tissue disorders as in Stickler syndrome.

\section{Acknowledgement}

We wish to thank Prof. Franco Laccone Department für Medizinische Genetik. Medizinische Universität, Vienna, Austria for performing the genetic test. We also wish to thank Prof. Hassan Gharbi ( Chairman of the Institute of Radiology and Research -Ibn Zohr Centre of Radiology, Tunis, Tunisia), for helping us in organizing and covering the required investigations for three families.

\section{Competing Interests}

The authors have declared that no competing interest exists.

\section{References}

1. Stickler GB, Belau PG, Farrell FJ, et al. Hereditary Progressive Arthro-Ophthalmopathy. Mayo Clin Proc. 1967; 40:433-455.

2. Stickler GB, Hughes W, Houchin P. Clinical features of hereditary progressive arthro-ophthalmopathy (Stickler syndrome): a survey. Genet Med. 2001; 3:192-196.

3. Richards AJ, Bguley DM, Yates JR, Lane C, Nicole M, Harper PS, Scott JD, Snead MP. Variation in the vitreous phenotype of Stickler syndrome can be caused by different aminoacid substitutions in the $\mathrm{X}$ position of the type II collagen Gly-X-triple helix. Am J Hum Genet. 2000; 67:1083-1094.

4. Francomano CA, Liberfarb RM, Hirose T, Maumenee IH, Streeten EA, Meyers DA, Pyeritz RE. The Stickler syndrome is closely linked to COL2A1, the structural gene for type II collagen. Pathol Immunopathol Res. 1988; 7:104-106. 
5. Snead MP, Yates JR. Clinical and molecular genetics of Stickler syndrome. J Med Genet. 1999; 36:353-359.

6. Liberfarb RM, Hirose T. The Wagner-Stickler syndrome. Birth defects. Orig Artic Ser. 1982; 18:525-538.

7. Niffenegger JH, Topping TM, Mukai S. Stickler's syndrome. Int Ophthalmol. 1993; 33:271-280.

8. Rose P, Ahn N, Levy HP, Davis J, Liberfarb RM, Nallamshetty L,Sponsellar PD, Francomono CA. Thoracolumbar spinal abnormalities in Stickler syndrome. Spine. 2001; 26:403-409.

9. Rose P, Ahn NU, Levy HP, Magid D, Davis JMS, Liberfarb RM, Sponseller PD, Francomono CA. The hip in Stickler syndrome. J Ped Orthopod. 2001; 21(5):657-663.

10. Al Kaissi A, Klaushofer K, Grill F. Osteochondritis dissecans and Osgood Schlatter disease in a family with Stickler syndrome. Pediatr Rheumatol J Online. 2009; 7:4.

11. Rose PS, Levy HP, Liberfarb RM, Davis J, Szymko-Bennett $Y$, Rubin BI, Tsilou E, Griffith AJ, Francomano CA Stickler syndrome: clinical characteristics and diagnostic criteria. Am J Med Genet A. 2005; 138A:199-207.

12. Al Kaissi A, Roschger P, Nawrot-Wawrzyniak K, Krebs A, Grill F, Klaushofer K. Evidence of reduced bone turnover and disturbed mineralization process in a boy with Stickler syndrome. Calcif Tissue Int. 2010; 86(2):126-31.

13. Forestier J, Rotes-Querol J. Senile ankylosing hyperostosis of the spine. Ann Rheum Dis. 1950; 9:321-30.

14. Resnick D, Niwayama G: Radiographic features of spinal involvment in diffuse idiopathic skeletal hyperostosis. Radiology. 1976;119:559-568.

15. Tonnis D, Heinecke A. Acetabular and femoral anteversion: relationship with osteoarthritis of the hip. J Bone Joint Surg Am. 1999; 81:1747-1770.

16. Joseph B. Treatment of internal rotation gait due to gluteus medius and minimus overactivity in cerebral palsy: anatomical rationale of a new surgical procedure and preliminary results in twelve hips. Clin Anat.1998; 11:22-8.

17. Chong KC, Vojnic CD, Quanbury AO, Letts RM. The assessment of the internal rotation gait in cerebral palsy: an electromyographic gait analysis. Clin Orthop Relat Res.1978; 132:145-50.

18. Murphy SB, Simon SR, Kijewski PK, et al. Femoral anteversion. J Bone Joint Surg Am. 1987; 69:1169-1176.

19. Van Huyssteen AL, Hendric MRG, Barnett AJ, Wakeley CJ, Eldridge JDJ. Cartilage-bone mismatch in the dysplastic trochlea: an MRI study. J Bone Joint Surg [Br] 2006; 81:688-91.

20. Kellgren JH, Lawrence JS. Radiological assessment of osteoarthritis. Ann Rheum Dis. 1957; 16:494-502.

21. Dejour H, Walch G, Nove-Josserand L, Guier C. Factors of patellar instability: an anatomic radiographic study. Knee Surg Sports Traumatol Arthrosc 1994; 2:19-26.

22. Wiberg G. Roentgenographic and anatomical studies on the patellofemoral. joint: With special reference to chondromalacia patella. Acta Orthop Scand $1941 ; 12: 319$

23. Harrison MM, Cooke TD, Fisher SB, Griffin MP. Patterns of knee arthrosis and patellar subluxation. Clin Orthop Relat Res.1994; 309:56-63.

24. Maroteaux P, Le Merrer M. Maladies osseuses de 1' enfant, 4 th edn. Paris: Medeicine-Sciences Flammarion. 2002. 